\title{
Organizational-Pedagogical Conditions to Form the Foreign Competence in Students with the Features of Linguistic Giftedness
}

\author{
Valentina Michailovna Panfilova ${ }^{1}$, Alexey Nikolaevich Panfilov ${ }^{1} \&$ Elena Efimovna Merzon ${ }^{1}$ \\ ${ }^{1}$ Kazan Federal University, Elabuga, Russia \\ Correspondence: Valentina Michailovna Panfilova, Kazan Federal University, Kazanskaya Street 89, \\ 423600, Elabuga, Russia.
}

Received: October 15, 2014 Accepted: November 19, 2014 Online Published: January 28, 2015

doi:10.5539/ies.v8n2p176

URL: http://dx.doi.org/10.5539/ies.v8n2p176

\begin{abstract}
The study of foreign competence at the present stage of the higher education development becomes more relevant. The article emphasizes the organizational-pedagogical conditions, providing the formation of foreign competence in students with the features of linguistic giftedness. The way to reveal the students, who have the features of linguistic giftedness, is presented. Experimental teaching showed the increased level of independent behavior in the process of foreign language study; the work in small groups on solution of linguistic tasks to the fullest extent actualizes potential linguistic abilities of students; the satisfaction with the learning process of subject "Foreign Language" has also increased.
\end{abstract}

Keywords: foreign competence, features of linguistic giftedness, organizational-pedagogical conditions

\section{Introduction}

\subsection{Foreign Competence as a Research Subject}

A dominant of modern system of the Russian higher pedagogical education is the development of scientific bases for pedagogical process, aimed at training of competent specialist, able to solve effectively the formulated practically-oriented tasks. Native secondary education requires a mobile, erudite teacher, thinking freely and critically, ready for professional activity in permanently-changing conditions, what, at present, seems to be impossible without second-language skills. It actualizes the development of foreign competence of the future teacher, assimilating the non-language profession.

For a long time, foreign competence has been a subject of psychological-pedagogical, methodological and linguistic investigations. The problems of improvement of foreign education of students in the higher educational institution are described in the investigations of such scientists Zimnaya (2005), Alderson (1996), Hutchinson and Waters (1987), Edge and Richards (1996).

The majority of researchers study the foreign competence as a component of professional competence. In this connection, despite the fact, that the foreign competence, for a long time, has been a subject of psychological-pedagogical, methodological and linguistic investigations, its study at the present stage of the higher education development becomes more relevant. A formulation of quality problem of students professional training, taking into consideration the requirements of the Federal State Educational Standard of the higher education of the third generation (FSES-3), makes actual to distinguish the linguistic competence from the proper professional competence, as well as to consider its essence, structure and content in the aspect of new requirements of modern higher professional education.

The analysis of scientific literature shows, that, alongside with the notion "foreign competence", a synonymic notion "foreign communicative competence" is also widely used. Thus, in the opinion of Proshyants, the foreign competence is understood as a "complex of sociocultural, linguistic knowledge, abilities and skills, implemented by the subject according to the communicative task in conditions of foreign environment. As a basic notion, the foreign competence can be considered as a system of cooperating elements, such as linguistic, linguo-cultural, sociocultural, professional-foreign, communicative competencies" (Proshyants, 2010, pp. 34-35). 


\subsection{The Characteristics of Components of Foreign Competence}

It shall be noted that a number of native researchers, such as Gez and Zimnaya, define the foreign competence quite narrowly, as an ability to understand and produce the infinite number of sentences, correct in linguistic relation, by means of conventional linguistic signs (Gez, 1985; Zimnaya, 2005). These abilities are based on communicative skills, shown in appropriate means of communication (speaking, listening comprehension, reading and writing):

- speaking, as a communication mode and an integral part of speaking activity, presupposes the presence and formation of lexical, grammatical and pronouncing skills of speaking; the ability to use the speech etiquette (greeting, invitation, request, refusal, apology); the ability to express the main speech functions (to confirm, to express, to doubt, to approve, to promise); the ability to speak expressively and to speak up integrally, cohesively and logically; the ability to speak independently and to speak up productively, ad lib. and in normal pace; the ability to retell, what was read, listened and also to communicate, what was seen;

- listening comprehension involves the development of lexical, grammatical, perceptive skills of listening comprehension; phonemic audition and auditory span; the ability to perceive, identify, understand and interpret the message, to check back, to anticipate, to understand the speech in normal pace, in phonetic notation, to understand the utterances of different character and style, to understand general content; the ability to understand the main idea, meaning of the text, to choose the main from the utterances;

- reading involves the perception of the written text; the ability to recognize the handwriting, the ability to identify, understand, interpret the text; the development of reading skills for search and detail; the ability to choose the material for reading, to read rather quickly and to guess the meaning of unknown words, to use the dictionary and other reference materials; the ability to use additional sources, to understand the main idea, meaning, content of the text, and, moreover, to choose the main from what was read;

- writing is the ability to organize, to formulate the message, the ability to handwrite and to type the text; it involves lexical, grammatical and graphical skills of writing; to write rather quickly and to choose the required information, to fix the main ideas, to draw up a plan and a thesis of the utterance; to write everyday and business letters, to fill in the definite types of commercial documents (Kostyukova \& Morozova, 2011, p. 47).

Foreign researchers, for instance, J. Raven and N. Khomsky, expand this notion, involving the following components:

- linguistic (the knowledge of vocabulary, phonetics, grammar and equivalent skills),

- sociolinguistic (reflects sociocultural conditions of language use),

- pragmatic (presupposes the implementation of communicative function, the production of speech acts) (Raven, 2002; Khomsky, 1972).

Yan Van Ek suggests another structure of foreign competence, according to which the following components are distinguished: linguistic, sociocultural, sociolinguistic, strategic, discursive, social (Van Ek, 1990).

The researchers note that the components of foreign competence should not be considered as independent from each other, as they present different sides of the integral foreign competence. It is essential, that among the components of foreign competence, distinguished by the majority of researchers, the content of some, for instance, sociocultural and sociolinguistic components, falls beyond the scope of only knowledge and skills, specific for the foreign language, and involves the skills, connected with the definite level of social competence of the future specialist.

\subsection{Professional Orientation of Foreign Competence}

However, it shall be noted that neither of mentioned models specifies the elements in its component part, associated with human professional activity. Kostyukova and Morozova mention, that in current conditions of development of the higher professional education in the process of passing to FSES-3, it is insufficient to be limited to linguistic and sociolinguistic aspects of foreign competence, not paying enough attention to professional orientation of language training of the future specialists. Kostyukova and Morozova define the foreign competence as "a situational category, reflecting an ability of the future specialist to implement knowledge-professional and linguistic (grammar, vocabulary, phonetics), foreign communicative skills (to bring the effective communication into action); professional-personal qualities of the student (communicativeness, tolerance, ability to overcome the psychological barrier in communication in another language) and the experience of foreign professional communication, promoting the creative solution of different practically-oriented tasks, appearing in the process of studying" (Kostyukova \& Morozova, 2011, p. 10). 
The investigation of Galimzyanova also underlines the professional orientation of foreign competence components, which the author determines as a complex system, integrative continuity of foreign and professionally domain knowledge, skills and abilities, motivation and understanding of foreign information, reflection and ability to self-management. In the structure of foreign competence, the author distinguishes the linguistic, communicative and pragmatic competencies. To the first group-linguistic-the author refers the main competencies, determining the knowledge of oral and written foreign speech, at that, if the linguistic competence is shown as a sum of knowledge about language, the ability to discriminate and to use the linguistic elements correctly, then the speech competence can be presented as the speech behavior according to the task of communication, as a linguistic system in action using the linguistic means, consistencies of their functioning to build the utterances-from the simplest expression of feelings to communication of nuances of intellectual and professional information. The second group-communicative-involves the professional-communicative (an ability to use the linguistic and speech means adequately for the purposes of communication tasks; it is also based on the ability to build the speech behavior taking into consideration professional communicative situations and ability for the communicative foreign activity in the professional sphere) and intercultural competencies (a definite combination of knowledge about culture of the studied foreign language). The third group of competencies-pragmatic-is presented by information-technological and self-educational competencies, which, being interdependent, have the common purposes. Information-technological competence is based on abilities to search for the required professionally significant information and to take it out from various sources, to convert it from one sign system to another, to evaluate it and to communicate the content of this information according to the formulated task, and also to use the Internet resources productively in the process of professional activity. The development of self-educational competence is connected with the ability to enrich knowledge in the process of individual searching and creative activity (Galimzyanova, 2009, pp. 19-20).

Some authors introduce the notion of "foreign professional communicative competence". Thus, the investigation of Mikhailova, the professional-foreign competence of students is determined as "the ability and readiness of future specialists to solve the communicative tasks in the sphere of professional activity, bringing into action the foreign communication with native speakers, searching and analyzing the information, required to study the foreign experience, and also the ability to work with scientific-technical literature and documentation in foreign language in the sphere of selected specialization, using the means of informational and communicative technologies" (Mikhailova, 2012, p. 8).

In the opinion of Andrienko, the notion "foreign professional communicative competence" is determined as "the ability of future specials to bring into action the professionally oriented communication as a secondary linguistic personality; to interact with the bearers of another culture, taking into consideration national values, standards and views; to create positive thinking for communicants in communication; to select communicatively viable ways of verbal and nonverbal behavior, based on knowledge about science and culture of the other nations under the polylogue of cultures; to preserve national self-identification in conditions of international integration and mobility" (Andrienko, 2007, p. 10). Structural-informative model of foreign professional communicative competence consists of the combination of the following key (basic) competencies: linguistic, discursive, strategic; sociocultural, pragmatic (social), linguo-professional, social-informative, social-political, personal (private, individual) (Andrienko, 2007).

\subsection{Foreign Competence as an Integrative Personal-Professional Education}

As per Nikitina, the foreign competence presents the integrative personal-professional education, which determines the ability of the future specialist to solve the problems and typical tasks, emerging in professional and socially determinated situations, using the knowledge of foreign language. The components of foreign competence are the linguistic, speech, sociocultural, compensating and educational-cognitive competencies (Nikitina, 2010). The author considers the professional-foreign competence as a complex of three components: motivational-value-conscious (the interest to professional-foreign training and understanding of its significance for future career; the understanding of necessity to use the means of informative and communicative technologies in future professional activity; the interest to different types of educational and professional activity, using the means of informative and communicative technologies at the lessons on professional-foreign training etc.); cognitive-pragmatist (uniting foreign communicative competence in the sphere of professional activity and common cultural competencies, including the informative ones) and emotional-volitional (connected with adequate self-esteem of abilities and elaboration of sense of responsibility for the successes in educational future professional activity) (Nikitina, 2010, p. 17).

Thus, the formulation of quality problem of students' professional training, based on the requirements of the FSES 3 of the higher education, makes actual to distinguish the foreign competence, and also the necessity to 
consider its essence, structure and content in the aspect of new requirements to the higher education.

\subsection{Formedness of Foreign Competence in Students with the Features of Linguistic Giftedness}

The level of formedness of foreign competence in students, studying the foreign language, is different. From our point of view, one of the reasons is a significant variation of students' linguistic abilities: from low abilities to the linguistic giftedness. We understand the linguistic giftedness as a number of individual-psychological constitutions of a personality, characterizing the increased level of intellectual, communicative, linguistic abilities, providing a stable motivation in language study, easiness and speed of language assimilation, creativity in selection of communication ways in foreign language, effectiveness of language use in the process of professionally oriented foreign communication. A student with the features of linguistic giftedness is characterized by the following individual-psychological traits: he has a stable motivation for foreign language study; the increased level of intellectual, communicative and linguistic abilities; demonstrates easiness and quickness in acquisition of linguistic knowledge; he is characterized by creativity in selection of ways for communication in foreign language and efficiency of language use in the process of professionally oriented foreign communication. Then, the foreign competence of students with the features of linguistic giftedness is understood as the integrative personal-professional education, which determines the student ability and readiness for creative solution of practically oriented and informative-communicative tasks in the sphere of professional activity and foreign professionally oriented communication with the native speakers in conditions of foreign environment (Panfilova, 2014). A number of topical issues emerges: is there a connection between the characteristics of students linguistic giftedness and formation of foreign competence, in what organizational-pedagogical conditions the foreign competence is being successfully formed in students with the features of linguistic giftedness.

\section{Procedure}

\subsection{Revelation of Students' Linguistic Giftedness}

In order to reveal a linguistic giftedness, there were tested the students, studying non-language specialties (the faculties of pedagogies and psychology, biology, physics-mathematics, economics and management). The selection control constitutes 194 people. The following methods were used: "The investigation of linguistic analysis" (High level of formedness of linguistic analysis is connected with the quality of dynamics of acquisition and speaking both native and foreign languages, facilitates individual orientation in language, serves as an indicator of linguistic capacity); "A diagnostics of mechanism of probabilistic forecasting" (The probabilistic forecasting is understood as the anticipation of future. According to such forecast, the preparation to relevant actions is carried out. In this content-to speech actions. The ability to select the words of the phrase correctly, taking into consideration the former context, preceding the new one, preconditions one of the most important components of human speech activity) (Panfilov \& Panfilova, 2014). In order to reveal motivation to study a foreign language, the test-questionnaire of Dubovitskaya was used (A peculiar characteristic of the procedure is that not the motivation of educational activity in whole is studied, but the specificity of motivation of educational activity, manifested in study of definite educational subjects, in our case-"Foreign Language") (Dubovitskaya, 2002).

The dispersion of IQ index of the respondents constitutes from 102 to 113, i.e. the index of the respondents is above the average. Motivation of students of non-linguistic specialties to study the foreign language has rather high indices- $57 \%$ respondents (see Table 1 ).

Table 1. Diagnostics of learning motivation orientation

\begin{tabular}{llll}
\hline & $\begin{array}{c}\text { Faculty of Philology and } \\
\text { Journalism }\end{array}$ & $\begin{array}{c}\text { Faculty of } \\
\text { Biology }\end{array}$ & $\begin{array}{c}\text { Faculty of Psychology and } \\
\text { Pedagogy }\end{array}$ \\
\hline $\begin{array}{l}\text { level of development of intrinsic } \\
\text { motivation }\end{array}$ & $\begin{array}{l}\text { high - } 63 \% \\
\text { average - } 28 \%\end{array}$ & high - 55\% & high - 53\% \\
& low - $9 \%$ & average - 27\% $\%$ & average - $24 \%$ \\
& low - $18 \%$ & low - 23\% \\
\hline
\end{tabular}

The average index of the short-term memory level is 7 points from 9 (see Table 2). 
Table 2. Study of short term memory

\begin{tabular}{llll}
\hline \multirow{2}{*}{ Method of study of short term memory } & Faculty & & \\
\cline { 2 - 4 } & Philology and Journalism & Biology & Psychology and Pedagogy \\
\hline Words (quantity) & 17 & 13 & 15 \\
Numbers (quantity) & 13 & 16 & 15 \\
average level of short-term memory in points & 7 & 7 & 7 \\
\hline
\end{tabular}

The development level of linguistic analysis: $52 \%$ of respondents have a high level. The level of formedness of probabilistic forecasting mechanism: $54 \%$ of respondents have a high level (see Table 3 ).

Table 3. Levels of linguistic analysis and mechanism of formation of probabilistic forecasting

\begin{tabular}{|c|c|c|c|}
\hline \multirow[b]{2}{*}{ Method } & \multicolumn{3}{|c|}{ Faculty } \\
\hline & $\begin{array}{l}\text { Philology and } \\
\text { Journalism }\end{array}$ & Biology & $\begin{array}{l}\text { Psychology and } \\
\text { Pedagogy }\end{array}$ \\
\hline \multirow{3}{*}{$\begin{array}{l}\text { Study of linguistic analysis (level of } \\
\text { development) }\end{array}$} & high $-60 \%$ & high - 48\% & high - 49\% \\
\hline & average $-30 \%$ & average - $33 \%$ & average $-35 \%$ \\
\hline & low $-10 \%$ & low $-19 \%$ & low $-16 \%$ \\
\hline \multirow{3}{*}{$\begin{array}{l}\text { Diagnostics of probabilistic forecasting } \\
\text { mechanism (level of development) }\end{array}$} & high - 65\% & high - 46\% & high - 51\% \\
\hline & average - $28 \%$ & average - 39\% & average - $35 \%$ \\
\hline & low - $7 \%$ & low $-15 \%$ & low $-14 \%$ \\
\hline
\end{tabular}

Based on the analysis of the obtained diagnostic and data of postdiagnostics interview, there was distinguished a group of "students with a linguistic giftedness", consisting of 51 persons, what constitutes $26 \%$ of the primary selection. The additional investigation was carried out with this group. The students with the linguistic giftedness were suggested to write an essay to the topic "My successes in studying of the foreign language in the higher educational institution". The essay text was investigated by means of content-analysis. The following units of the analysis were distinguished: 1) satisfaction of students with their existing level of foreign competence; 2) consideration of linguistic abilities in the process of foreign competence formation. The analysis of data, recorded in coding matrix, provided us with the opportunity to make the following conclusions: the students with the features of linguistic giftedness are not satisfied with the formedness level of their foreign competence; they consider, that their linguistic potential is not used to the fullest extent, that the traditional methods for foreign language teaching do not allow assimilating the language at the higher level; the higher the level of linguistic giftedness is, the more the dissatisfaction with traditional technologies to form the foreign competence is expressed.

Thus, the empiric investigation allowed formulating the organizational-pedagogical task, which is to be solved: to create special organizational-pedagogical conditions for foreign language assimilation for the students, who have the features of linguistic giftedness; to construct the individual educational route to study the foreign language for those students, who expressed the desire to work individually.

There were formed two groups of students, who have the features of linguistic giftedness: control and experimental. The special organizational-pedagogical conditions were created in the experimental group.

\subsection{Technologies to Form the Foreign Competence in Students with the Features of Linguistic Giftedness}

The formation of foreign competence in students with the features of linguistic giftedness, but not just the sums of knowledge, skills and abilities, also presupposes the search for new educational methods and technologies. The most prospective ones, in the case of training the students with high level of abilities, are the developing technologies, based on active, reflexive-pragmatist forms and educational methods, to which belong the following:

- the technologies of problem-module education, which are implemented on the basis of educational program for the subject, made in the view of modules, that presupposes independent or partially independent study of the 
material by the student, with knowledge revision and its use in practice for task solution, self-control and check (for instance, by means of testing) of obtained results, self-evaluation and correction of educational-cognitive activity. The implementation of problem-module education provides its individual character, regulation of work pace, degree of problematicity and scope of educational material, the level of task complexity, support a high level of cognitive activity and independence of students;

- educational procedures as an educational investigation, in the course of which the students carry out the following types of activity: 1) the problem facing, 2) the data collection - "verification", 3) the data collection experimentation, 4) the planning of investigation, 5) the analysis of course of investigation, 6) the conclusions, reflection of results. In the process of educational investigations, the students make mental efforts (analysis, synthesis, generalization, classification, systematization, verification of data validity etc.), based on which they develop intellectual abilities and communicative skills;

- communicative technologies (brainstorm, discussion, press-conference, debate-dialogue, educational debates and other active forms and methods), aimed at organization of work in group and at collaboration, at formation of students universal skills, connected with accommodation of interests and setting of general aims of activity, projecting of ways of activity, analysis and presentation of information or obtained results, self-presentation, culture of substantiation of your own judgments, understanding and evaluation of different viewpoints, decision making and others (Kasper \& Kellerman, 1997; Canale \& Swain, 1980).

In formation of foreign communicative competence in students with the features of linguistic giftedness, a significant didactic potential belongs to the informational technologies, which involve the students to the foreign professional activity, develop linguistic skills and speech abilities, and teach to use electronic reference materials, dictionaries. At present, mixed educational forms, combining different methods, act as effective ones in didactic innovations. In this connection, in training of students with the features of linguistic giftedness, a web-quest technology for foreign language teaching is presented as quite relevant, as, being based on project methods, integrates both program, group and communicative method, as well the problem method, a method of conversation. According to the investigation of Baguzina, the analysis of experience of web-quest implementation and approbation in the sphere of foreign language teaching, provides an opportunity to develop the skills of informational activity, to form positive emotional relation to the cognitive process, to increase motivation of studying, the quality of acquired knowledge on the studied subject, to develop the students creative potential, to form general skills of acquirement strategy to assimilate the educational material. At that, the themes of web-quests can be different, the problem tasks can differ in the degree of complexity (Baguzina, 2012).

\subsection{Organizational-Pedagogical Conditions to Develop the Foreign Competence in Students with the Features of Linguistic Giftedness}

The abovementioned technologies provided a basis for development of organizational-pedagogical conditions to develop the foreign competence in students with the features of linguistic giftedness (didactic, educational-methodological and organizational-technical).

A didactic condition to develop the foreign competence in students with the features of linguistic giftedness involves the following: specification of educational content on the subject "Foreign Language"; the study of practically-oriented oral topics; the provision of dialogueness in communication of all participants of the educational process in the course of subject-subject relations; the expansion of content of foreign education due to inclusion of extracurricular types of activity; the organization of reflection as a personal understanding, analysis of proper foreign communicative activity; the discussion of previously reasoned problems, including the ones, which spontaneously appear in the course of practically-oriented communication; the execution of educational-research works, using the literature in foreign language, which involve summaries, articles, thesis, reviews, reports etc.

Educational-methodological conditions to develop the foreign competence in students with the features of linguistic giftedness presuppose the development and implementation of specially created training pack (TP) on the subject. A training pack is oriented at organization of subject-subject relations in the range of thesis of competence, personally-oriented and pragmatist approaches, accepted in the work, and it is achieved due to the following: the creation of different in structure professionally-oriented educational situations in Foreign Language classes; granting the student a right for individual selection; permanent correction of the created educational situations, aimed at the development of foreign competence of the student.

Organizational-technical conditions to develop the foreign communicative competence presupposes the presence and active use of possibilities of modern training equipment (computers, audio-video facilities etc.) and Internet-resources in the course of teaching the discipline "Foreign Language" in the process of organization of 
different forms of activity (educational, quasi-professional and educational-professional).

The experimental group was aimed at the increase of foreign competence at implementation of abovementioned organizational-pedagogical conditions for the foreign language study. The students of experimental group acquired the experience to solve different tasks, executing the social roles and functions, based on formed knowledge, universal abilities, referring to different spheres of social life. This group used active educational methods, by means of inclusion of students to specially created educational situations, imitating vital and professional problems (business games, role playing, discussions, conferences, projects, disputes). The experimental education took place during one term, the control and experimental groups were subject to the repeated investigation, using the same parameters.

\section{The Results and Their Discussion}

The developed and experimentally checked organizational-pedagogical conditions (didactic, educationalmethodological and organizational-technical) allow increasing the level of foreign competence in students with the features of linguistic giftedness in the process of assimilation of the discipline "Foreign Language" by the students. It was found out, that the key pedagogical condition for effective development of foreign competence in students with the features of linguistic giftedness are the developing technologies, based on active, reflexive-pragmatist and informative-communicative forms and methods of education.

It was proved by the following. The level of motivation to study the discipline "Foreign Language" in experimental group increased up to $63 \%$, and in the control group, it stayed at the former level-57\% (see Table 4).

Table 4. Values of the level of motivation to study discipline "Foreign Language" in experimental and control groups

\begin{tabular}{|c|c|c|c|c|c|c|}
\hline \multirow[t]{2}{*}{$\#$} & \multicolumn{2}{|c|}{ Samples } & \multicolumn{2}{|c|}{ Deviations from average } & \multicolumn{2}{|c|}{ Squared deviations } \\
\hline & Experimental Group (EG) & Control Group (CG) & EG & $\mathrm{CG}$ & EG & $\mathrm{CG}$ \\
\hline 1 & 19 & 15 & 2.68 & 2.64 & 7.1824 & 6.9696 \\
\hline 2 & 18 & 16 & 1.68 & 3.64 & 2.8224 & 13.2496 \\
\hline 3 & 19 & 15 & 2.68 & 2.64 & 7.1824 & 6.9696 \\
\hline 4 & 19 & 16 & 2.68 & 3.64 & 7.1824 & 13.2496 \\
\hline 5 & 20 & 15 & 3.68 & 2.64 & 13.5424 & 6.9696 \\
\hline 6 & 18 & 16 & 1.68 & 3.64 & 2.8224 & 13.2496 \\
\hline 7 & 19 & 15 & 2.68 & 2.64 & 7.1824 & 6.9696 \\
\hline 8 & 19 & 16 & 2.68 & 3.64 & 7.1824 & 13.2496 \\
\hline 9 & 20 & 16 & 3.68 & 3.64 & 13.5424 & 13.2496 \\
\hline 10 & 19 & 17 & 2.68 & 4.64 & 7.1824 & 21.5296 \\
\hline 11 & 18 & 15 & 1.68 & 2.64 & 2.8224 & 6.9696 \\
\hline 12 & 19 & 15 & 2.68 & 2.64 & 7.1824 & 6.9696 \\
\hline 13 & 19 & 16 & 2.68 & 3.64 & 7.1824 & 13.2496 \\
\hline 14 & 18 & 17 & 1.68 & 4.64 & 2.8224 & 21.5296 \\
\hline 15 & 19 & 8 & 2.68 & -4.36 & 7.1824 & 19.0096 \\
\hline 15 & 12 & 9 & -4.32 & -3.36 & 18.6624 & 11.2896 \\
\hline 17 & 13 & 8 & -3.32 & -4.36 & 11.0224 & 19.0096 \\
\hline 18 & 14 & 9 & -2.32 & -3.36 & 5.3824 & 11.2896 \\
\hline 19 & 12 & 8 & -4.32 & -4.36 & 18.6624 & 19.0096 \\
\hline 20 & 11 & 9 & -5.32 & -3.36 & 28.3024 & 11.2896 \\
\hline 21 & 13 & 7 & -3.32 & -5.36 & 11.0224 & 28.7296 \\
\hline 22 & 13 & 7 & -3.32 & -5.36 & 11.0224 & 28.7296 \\
\hline
\end{tabular}




\begin{tabular}{lcccccc}
\hline 23 & 12 & 8 & -4.32 & -4.36 & 18.6624 & 19.0096 \\
24 & 12 & 9 & -4.32 & -3.36 & 18.6624 & 11.2896 \\
25 & 13 & 7 & -3.32 & -5.36 & 11.0224 & 28.7296 \\
Total & 408 & 309 & -0 & 0 & 255.44 & 371.76 \\
Average & 16.32 & 12.36 & & & & \\
\hline
\end{tabular}

To assess the significance of differences in the level of motivation in students with signs of linguistic giftedness of study groups we used the method of counting the Student t-criterion. Critical values were obtained: at $p \leq 0.05$ the critical value of 2.01, at $p \leq 0,01$ critical value of 2.68. Axis of significance was defined (see Figure 1).

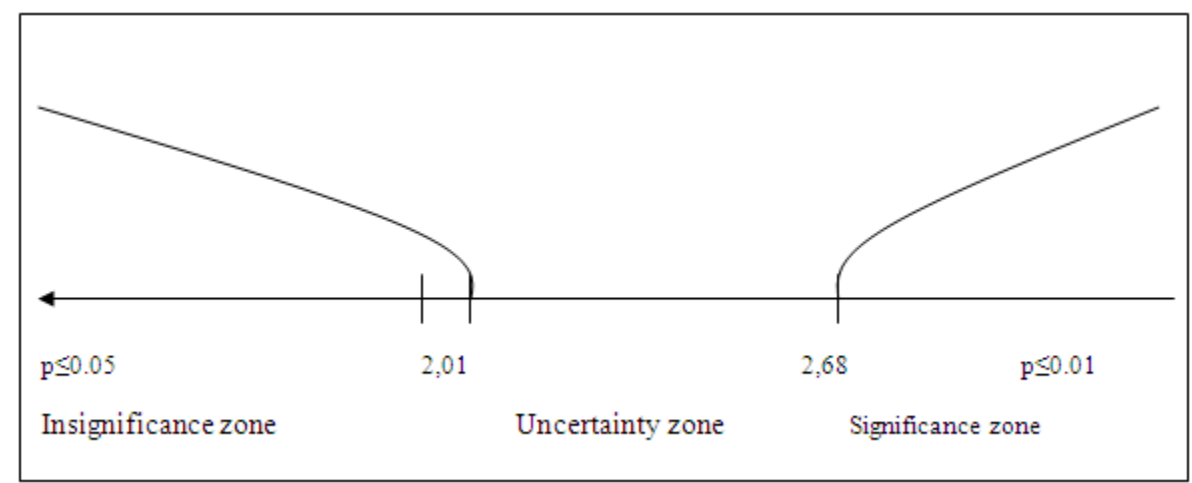

Figure 1. The axis of significance in the comparison of indicators of intrinsic motivation

Analysis of the data shows that the $t_{\mathrm{emp}}=3.9$ is in the area of significance. A statistically significant difference by the motivational component of foreign language competence of students was revealed that demonstrates that the students in the experimental group significantly differ from the control group of students by a high level of motivational component, reflecting the educational and professional motives and values. These results reflect the fact that the organizational and pedagogical conditions lead to an increase in the level of foreign language competence of students with linguistic signs of giftedness.

The level of foreign competence was determined based on average grade of rating (grade-rating system for knowledge evaluation as per 100-grade scale). The experimental group demonstrated the average - 89 , the control one - 78. The participants of the experiment were suggested to work with the text of their essay, written in the recital of the experiment, and to make changes, if they want. The text of the reworked essay was investigated by means content-analysis, based on the following units of analysis: 1) satisfaction of students with their level of foreign competence; 2) consideration of linguistic abilities in the studying process of the discipline "Foreign Language". The conclusions after the text handling are the following. In the control group, satisfaction with the technology of foreign competence formation was not changed. In the experimental group, it was mentioned, that: 1) the level of independence in foreign language study was increased; 2) the work in small groups to solve the linguistic problems provides an opportunity to actualize the linguistic abilities; 3) satisfaction with the assimilation process of the discipline "Foreign Language" was increased.

\section{Conclusion}

Theoretical analysis of literature allowed determining the theoretical approaches to understanding of foreign competence of linguistically gifted students, the content of notions "foreign competence", "linguistic giftedness", allowed developing the author's model to form the foreign competence in students with the features of linguistic giftedness, and also to reveal psychological-pedagogical conditions for its formation.

The foreign competence is considered as a complex, multi-component formation, at that, in the process of linguistic training, the attention is focused on professional orientation of students' foreign competence. Foreign competence of students with the features of linguistic giftedness is understood as an integrative personalprofessional formation, which determines the ability and readiness of student to creative solution of practically-oriented and informative-communicative tasks in the sphere of professional activity and foreign professionally oriented communication with the native speakers in conditions of foreign environment. 
The investigation determines, that the students with the features of linguistic giftedness are characterized by the following individual-psychological traits: they have stable motivation to study the foreign language, the increased level of intellectual, communicative and linguistic abilities, demonstrate easiness and quickness of getting the linguistic knowledge, they are characterized by creativity in selection of ways to communicate in foreign language and effectiveness of language use in the process of professionally oriented foreign communication.

There were distinguished the organizational-pedagogical conditions, providing the formation of foreign competence in students with the features of linguistic giftedness; they are based on organization of educational process using the principles of discovery learning, the provision of creative foreign didactic environment. A didactic condition to develop the foreign competence in students with the features of linguistic giftedness are the developing technologies, based on active, reflexive-pragmatist and informative-communicative forms and methods of education.

At the stage of ascertaining experiment, at determination of initial level, structure and content of foreign competence in students with the features of linguistic giftedness, we faced some problems in research. It turned out that it is difficult to describe the criteria, indices and methods of evaluation of foreign competence in students with the features of linguistic giftedness, as the foreign competence and linguistic giftedness have complex integrated nature.

A level analysis of components of foreign competence in students with the features of linguistic giftedness showed, that the cognitive component, reflecting professional and linguistic knowledge, the operational-effectual component, reflecting the ability to implement foreign professional communication, motivational-valueconscious component, reflecting educational-professional motives and values, are at advanced development level. The highest level of development was revealed per cognitive component of foreign competence, demonstrating the domination of "knowledge" model of modern education. A reflexive component of foreign competence, reflecting the ability for self-analysis, the ability to determine individually your own educational path - to set goals, to bear responsibility for the final result - is at optimal level of development in students with the features of linguistic giftedness. These results show, that students with the features of linguistic giftedness, in the course of acquisition of the discipline "Foreign Language", assimilate those components of the foreign competence to a greater extent, that are connected with knowledge acquisition, the ability to use them in foreign-professional communication, the ability to fulfill self-regulation of educational-professional activity. However, a reflexive component of foreign competence, shown in the ability to plan and to control the intermediate and final results of activity, in adequacy of self-concept and formedness of subjective criteria of educational activity success, in self-sufficiency and independence in the process of fulfillment of educational-professional tasks, requires further development.

\section{References}

Alderson, J. C., \& Beretta, A. (1992). Evaluating Second Language Education. Cambridge: Cambridge University Press. http://dx.doi.org/10.1017/CBO9781139524575

Andrienko, A. S. (2006). Development of foreign professional communicative competence in students of Technical Higher Professional Institute (based on credit-module educational technology) (M. S. thesis, Rostov-on-Don).

Baguzina, E. I. (2012). Web-quest technology as a didactic mean to form the foreign communicative competence: As exemplified by the students on non-language institute ( $\mathrm{PhD}$ thesis, MSU, Moscow).

Canale, M., \& Swain, M. (1980). Theoretical Bases of Communicative Approaches to Second Language Teaching and Testing. Applied Linguistics, 1, 1-47. http://dx.doi.org/10.1093/applin/I.1.1

Dubovitskaya, T. D. (2002). Diagnostic Technique for Orientation of Educational Motivation. Psychological Science and Education, 2, 42-45.

Galimzyanova, I. I. (2009). Pedagogical system of foreign communicative competence formation in future engineers (M.S. thesis, Kazan).

Gez, N. I. (1985). Formation of Communicative Competence as an Object of Methodological Investigation. Foreign Languages at School, 2, 18.

Hutchinson, T., \& Waters, A. (1987). English for Special Purposes: A Learning-Centered Approach. Cambridge. http://dx.doi.org/10.1017/CBO9780511733031

Kasper, G., \& Kellerman, E. (1997). Communication Strategies: Psycholinguistic and Sociolinguistic Perspectives. New York: Addison Wesley Longman. http://dx.doi.org/10.1017/s0272263199244063 
Khomsky, N. (1972). Language and Mentality. Publications of Structural and Applied Linguistics. Issue 2, MSU Publisher.

Kostyukova, T. A., \& Morozova, A. L. (2011). Development of Foreign Competence in Students of Non-Language Institutes. Tomsk: Tomsk Polytechnical University Publisher.

Mikhailova, E. B. (2012). Formation of professional-foreign competence in students of engineering specialties, using the means of informative and communication technologies (M. S. thesis, Nizhny Novgorod).

Nikitina, E. G. (2010). Development of foreign competence in students of the institute, using the means of module education: As exemplified by the economic specialties (M. S. thesis, Cheboksary).

Panfilov, A. N., \& Panfilova, V. M. (2014). Linguistic Giftedness of Students as a Basis for Foreign Educational Environment. The Science and the World, 3(7), 87-90.

Panfilova, V. M. (2014, July 6). Pedagogical Technologies to Form the Foreign Competence in Students with the Features of Linguistic Giftedness. Modern Problems of Science and Education, 3. Retrieved from http://www.science-education.ru/117-13705

Proshyants, N. A. (2010). Formation of Foreign Linguistic Competencies in Professional Discourse. A Scientific and Research Work, 3, 34-38.

Raven, J. (2002). Competence in Modern Society: Revelation, Development and Implementation. M.: Cogito-Center.

Van Ek, J. A., \& Trim, J. L. M. (1999). Waystage 1990. Council of Europe Conseil de l'Europe. Cambridge University Press. http://dx.doi.org/10.1017/CBO9780511667107

Zimnaya, I. A. (2005). Key Competencies as a Resultative Purposeful Basis for Competence Approach in Education. M.: Fenix.

Zimnaya, I. A. (2006). Competence-Based Approach. What is its Place in the System of Modern Approaches to the Educational problems? Theoretical-Methodological Aspect. Higher Education Today, 8, 20-26.

\section{Copyrights}

Copyright for this article is retained by the author(s), with first publication rights granted to the journal.

This is an open-access article distributed under the terms and conditions of the Creative Commons Attribution license (http://creativecommons.org/licenses/by/3.0/). 